\title{
Ozon uygulamasının devital ağartma yapılan dentinde rezin simanın shear bağlanma dayanımına etkisi
}

\author{
Betül Özçopur ${ }^{1}$, Özer Alkan², Öznur Eraslan³ ${ }^{3}$ Eylem Ayhan Alkan ${ }^{4}$, \\ Gürcan Eskitaşçıŏlu ${ }^{5}$
}

Başuru Tarihi: 25 Haziran 2013 Yayna Kabul Tarihi: 4 Nisan 2014

Selcuk Dental Journal, 2014; 2: 59-65

\section{Effect of ozone application on the shear bond strength of resin cements to nonvital bleached dentin}

Background: The aim of this study was to evaluate the bond strengths of two resin based cements bonded to ozon-treated or non-treated nonvital bleached dentin.

Methods: Eighty freshly extracted sound human maxillary incisor crowns were assigned to eight groups $(n=10)$ : $(G 1, G 2)$ bleached $(10 \%$ carbamide peroxide, Opalescence Boost \%38 Hydrogen peroxide) without or (G3,G4) with application of gaseous ozone $(40 \%, 50$ second, CR probe, Biozonix; High-Frequency Ozone Generator, Germany), (G5, G6) ozon treated without bleaching and (G7, G8) untreated control groups. The crowns were embedded in acrylic resin and dentin surfaces were exposed. Specimens were bonded with one of the two resin cements: Secure Cement (Sun Medical) (G1, G3, G5, G7); Clearfil Esthetic Cement (Kuraray) (G2, G4, G6, G8). $3 \times 3$ build-ups were created with the Resin cements and allowed to set (37으, $100 \%$ humid, $24 \mathrm{hrs}$ ) and then tested to failure for shear bond strength ( $0.5 \mathrm{~mm} /$ minute). The data was calculated as $\mathrm{MPa}$ and analyzed using Kruskal-Wallis test $(P<0.05)$.

Results: Combination of ozone treatment and bleaching resulted in increased bond strength on both Secure cement (G3) and Clearfil Esthetic cement (G4) specimens $(p>0.05)$. Secure cement specimens treated with ozone (G5) demonstrated significantly lower shear bond strengths than $G 1, G 3$, and $G 7(P<0.05)$. Significant increase in shear bond strength was detected in Clearfil Esthetic cement group (G4) when compared to untreated control group (G8).

Conclusion: Pretreatment with ozone prior to bonding procedure may decrease the effect of residual peroxide-induced reduction in resin bond strength. Thus, ozone application on nonvital bleached dentin surfaces can improve resin cement bonding to dentin surfaces.

KEY WORDS

Nonvital bleached dentin, rezin siman, ozone, shear bond strength
Renklenme dişlerde önemli estetik problemler oluşturur. Renklenmiş dişlerde ağartma, protetik restorasyon veya kombinasyonları tedavi seçenekleri olarak uygulanabilir. Ev tipi ve ofis tipi ağartma işlemleri günümüzde sıkça kullanılmaktadır. Sistemik nedenlere bağlı iç renklenmelerde protetik rehabilitasyon genellikle gereklidir (Rueggeberg ve Margeson 1990, Howell 1981, Cavalli ve ark 2001, Khoroushi ve ark 2009, Moosavi ve ark 2010, Türkün ve Türkün 2004).

Hidrojen peroksit en çok kullanılan ağartma ajanıdır. Serbest oksijen radikalleri ve perhidroksil iyonu $\left(\mathrm{HO}_{2}{ }^{-}\right)$varlığı ile kimyasal olarak renklenmiş organik moleküllerin renginin açılmasını sağlar (Khoroushi ve ark 2009). Ağartma alanından oksijen salınması reaksiyonun başlamasında önemli role sahiptir. Peroksitlerin dental sert dokularda modifikasyonlar ortaya çıkardığı ve organik ve inorganik komponentlerin oranını değiştirdiği bilinmektedir. Ağartma işleminden sonra diş yüzeyinde veya içinde oksijen artıklarının kaldığı bilinmektedir (Freire ve ark 2009). Bu artık

\footnotetext{
${ }^{1}$ Yüzüncü Yıl Üniversitesi, Diș Hekimliği Fakültesi, Endodonti Anabilim Dalı, Van

${ }^{2}$ Yüzüncü Yıl Üniversitesi, Diş Hekimliği Fakültesi, Ortodonti Anabilim Dalı, Van

${ }^{3}$ Selçuk Üniversitesi, Diş Hekimliği Fakültesi, Endodonti Anabilim Dalı, Konya

${ }^{4}$ Yüzüncü Yıl Üniversitesi, Diş Hekimliği Fakültesi, Periodontoloji Anabilim Dalı, Van

${ }^{5}$ Yüzüncü Yıl Üniversitesi, Diş Hekimliği Fakültesi, Protetik Diş Tedavisi Anabilim Dalı, Van
} 
materyal rezin monomerlerin polimerzasyonunu engeller ve dolayısıyla restorasyonların bağlanma dayanımını düşürür (Khoroushi ve ark 2009, Freire ve ark 2009).

Yapılan pek çok çalışmada ağartma uygulanan diş yüzeyine adezivlerin ve kompozit rezinlerin bağlantısı değerlendirilmiştir (Rueggeberg ve Margeson 1990, Howell 1981, Cavalli ve ark 2001, Khoroushi ve ark 2009, Moosavi ve ark 2010, Türkün ve Türkün 2004). Ağartmadan hemen sonra kompozit rezin uygulamasında bağlanma dayanımının ağartma uygulanmayan dişlere oranla daha düşük çıktığı gözlenmiştir (Freire ve ark 2009).

Ağartma sonrası bağlanma dayanımında oluşan problemleri ortadan kaldırmak amacıyla; yüzeyel dentinin uzaklaştırıması, ağartma işlemi uygulanan yüzeye alkol tatbiki, organik çözücüler içeren adezivlerin uygulanması gibi çeşitli teknikler uygulanmaktadır (Spyrides ve ark 2000, Shinohara ve ark 2004, Shinohara ve ark 2005). Bununla birlikte, birçok çalışmada, ağartma sonrasında daimi restorasyonun uygulamasından önce, 24 saat ile dört hafta arasında değişen sürelerde beklenmesi gerektiği bildirilmektedir (Türkün ve Türkün 2004, Freire ve ark 2009, Spyrides ve ark 2000, Shinohara ve ark 2004, Shinohara ve ark 2005, Kwon ve Kim 2013).

Gaziform ozon dental uygulamalarda alternatif olarak ve okluzal ve kök çürüklerinde minimal invaziv yaklaşımlarda kullanılmaktadır. Ozonun kök kanalında ve post boşluklarında dezenfeksiyon amacıyla kullanımıda gündemdedir (Dahnhardt ve ark 2006, Huth ve ark 2005, Knezevi'c ve ark 2007). Ozonun dental sert dokulara adeziv bağlantısında azalma ya da bağlanmayı artırıcı bir etkisinin bulunmadığını rapor eden çalışmalarda vardır (Schmidlin ve ark 2005, Azarpazhooh ve Limeback 2008). Bununla birlikte pek çok çalışma dezenfeksiyon ya da ağartma amacıyla diş yüzeyine uygulanan oksidan ajanların diş sert dokularının sertliğinde değişiklik oluşturduğunu bildirmektedir. Hidrojen peroksitin düşük dozda kullanımının dentin mikrosertliğinde değişiklik oluşturmadığı gösterilmiştir (Nagayoshi ve ark 2004, Versluis ve ark 1997). Ozon moleküllerinin yüksek reaktivitesi ve dişteki dehidratasyon miktarı gaz akışını etkiler ve dental sert dokuların yapısında değişiklik meydana getirebilir (Schmidlin ve ark 2005, DeHoff ve ark 1995). Ozon uygulamasının minenin fiziksel özelliklerine etkisi incelenmiş ve herhangi bir değişiklik oluşturmadığı bulunmuştur (Schmidlin ve ark 2005, DeHoff ve ark 1995).

Bu bilgilerin ışığında bu çalışmanın amacı, ağartma işlemi sonrası gaz ozon kullanımının dentine rezin siman bağlantısına etkinliğinin incelenmesidir.

\section{GEREÇ ve YÖNTEM}

Seksen adet çürüksüz insan kesici dişi toplandı. Diş kuronları mine-sement seviyesinden su soğutması altında aerator yardımıyla uzaklaştırıldı. Koronal pulpa tirnerf yardımıyla uzaklaştııılıktan sonra, ağartma işlemi uygulamadan once mine yüzeyi düşük hızda çalışan mikromotor ve pasta yardımıyla temizlendi ve rastgele sekiz gruba ayrılan dişlere sırasıyla aşağıdaki ağartma işlemleri uygulandı.

Grup 1: Ağartma (\%38 hidrojen peroksit, Opelescence Boost) ve Secure Cement

Grup 2: Ağartma (\%38 hidrojen peroksit, Opelescence Boost) ve Clearfil Esthetic Cement

Grup 3: Ağartma (\%38 hidrojen peroksit, Opelescence Boost), ozon uygulaması (Biozonix; High-Frequency Ozone Generator, Germany, 40\%, 50 second, CR probe, 2,100 ppm) ve Secure cement

Grup 4: Ağartma (\%38 hidrojen peroksit, Opelescence Boost), ozon uygulaması (Biozonix; High-Frequency Ozone Generator, Germany, 40\%, 50 second, CR probe, 2,100 ppm) ve Clearfil Esthetic Cement

Grup 5: Ozon uygulaması (Biozonix; High-Frequency Ozone Generator, Germany, 40\%, 50 second, CR probe, 2,100 ppm) ve Secure cement

Grup 6: Ozon uygulaması (Biozonix; High-Frequency Ozone Generator, Germany, 40\%, 50 second, CR probe, 2,100 ppm) ve Clearfil Esthetic Cement

Grup 7: Mine yüzeyine secure cement uygulaması (Kontrol 1)

Grup 8: Mine yüzeyine Clearfil Esthetic Cement uygulaması (Kontrol 2)

Ağartma yapılan dişlerde her örneğin bukkal yüzüne ve pulpa odasına 10 dakika \%38 hidrojen peroksit (Opalescence Xtra Boost; Ultradent Products Inc., South Jordan, UT, USA) uygulandı. Hem bukkal yüzeye hem de pulpa odasına 20 saniye ışık uygulandı (S-LED, Antos, USA). Bukkal yüzeydeki ajan su ile uzaklaştırıırken pulpa odasında ağartma ajanı pamuk yardımıyla yerleştirilerek üç gün bırakıldı. Uygulama altı günde iki kez olacak şekilde sonlandırıld ve pulpa kaviteleri geçici olarak restore edildi (Cavit, ESPE 3M; Norristown, PA, USA). Örnekler seanslar arasında $37^{\circ}{ }^{\circ}$ 'de nemli ortamda bekletildi. Bonding işlemlerinden önce ise örnekler 24 saat oda Isısında bekletildi. Kontrol grupları gün aşırı içlerinde bulundukları distile su değiştirilerek deney süresi sonuna kadar nemli ortamda bekletildi.

Ozon uygulama cihazı Biozonix ozon üreten elektrik devresine bağlı bir sistemdir (Biozonix; High-Frequency Ozone Generator, Germany). Ozon gazı (2,100 ppm $40 \%$ ) mine yüzeyine 50 saniye uygulandı. Ozon gazının 
direk inhalasyonundan kaçınmak için oda havalanması ve sakşının aktif çalışmasına özen gösterildi.

Ağartma ve ozon uygulaması sonrası deney grupları distile su içinde 24 saat (37으) bekletildi ve bonding işlemlerine geçildi. Bonding işlemleri öncesi örnekler diş fırçasıyla 10 saniye musluk suyu altında yıkandı. Aynı protokol kontrol grupları içinde uygulandı.

\section{Örnek hazırlanması:}

Örnekler $15 \times 18 \times 29 \mathrm{~mm}^{3}$ polietilen silindirler içine self-cure rezin kullanılarak, labial yüzeyleri dışarıda kalacak şekilde gömüldü. Mine yüzeyleri 0.5-1 $\mathrm{mm}$ derinliğinde su soğutması altında elmas frez yardımıyla uzaklaştırıldı ve 800-grit zımpara kağıdı ile yüzeyler polisajlandı (EcoMet 3, Buehler, IL, USA). Yüzeyler iki rezin simandan biriyle restore edildi: Secure Cement (Sun Medical) (G1, G3, G5, G7) ve Clearfil Esthetic Cement (Kuraray) (G2, G4, G6, G8).

Rezin simanların yerleştirilebilmesi için $3 \mathrm{~mm}$ çapında ve $3 \mathrm{~mm}$ yüksekliğinde plastik silindirler kullanıldı. Secure siman uygulamasında primer uygulandıktan sonra 20 saniye bekletildi ve hafif hava ile primer inceltildi. Eşit miktarda baz ve katalizör karıştırıldıktan sonra diş yüzeyine uyumlanan silindirler yardımıyla uygulandı ve 10 saniye ışık uygulandı.

Clearfil Esthetic siman primeri (ED primer II) diş yüzeyine uygulandı, 20 saniye bekletildi, 5 saniye arayla kurutulduktan sonra 10 saniye ışık uygulandı. Rezin siman iki kat olacak şekilde uygulandı ve 20 saniye ışık uygulandı (S-LED, Antos, USA). Örnekler 24 saat (37을 distile su içerisinde bekletildi ve shear-bond testi uygulandı (ELISTA, İstanbul, Turkiye).

\section{Shear bond testi:}

Shear testi $1 \mathrm{~mm} /$ dakika hızda bıçak sırtı şeklindeki uç yardımıyla diş ve rezin siman bağlantı yüzeyinden gelecek şekilde uygulandı. Ayrılma değerleri Newton (N) olarak kaydedildi ve $\mathrm{N}$ değerlerinin rezin blok taban alanına bölünmesiyle elde edilen megapaskal (MPa) değerleri olarak analiz edildi $\left(\mathrm{MPa}=\mathrm{N} / \mathrm{mm}^{2}\right)$.
Kopan bağlantı yüzeyleri stereoskopik microskop (X20-X40, Olympus SZ40, Japan) ile incelenerek, adeziv (A): rezin-mine yüzeyi kopması, mix (M): mine yüzeyinde ince bir tabaka yapıştırma simanı bulunan adeziv hata, koheziv (K): yapıştırma simanında kopma, Parsiyel koheziv (D): mine ya da rezin yüzeyinde şeklinde belirlendi.

\section{İstatistiksel analiz:}

Tanımlayıcı istatistik, ortalama, standart sapma, standart hata, minimum ve maksimum değerler ve hata modları test edilen tüm gruplar için hesaplandı (Tablo 1 ve Tablo 2). Gruplar arası bağlanma dayanımını karşılaştırmak için tek yönlü varyans analizi (ANOVA) and Kruskal-Wallis testleri kullanıldı. İstatistikler için SPSS 15.0.0 (SPSS Inc, Chicago, III) kullanıldı.

Tablo 1.

\section{Kullanılan materyallerin içerik, üretici firma, bonding prosedürü ve batch numaraları}

\begin{tabular}{|c|c|c|c|c|}
\hline Materyal & İçerik & $\begin{array}{l}\text { Üretici } \\
\text { firma }\end{array}$ & $\begin{array}{l}\text { Bonding } \\
\text { prosedürü }\end{array}$ & Batch \# \\
\hline $\begin{array}{l}\text { Secure } \\
\text { Siman } \\
\text { Self } \\
\text { etching, } \\
\text { Dual } \\
\text { Cure }\end{array}$ & $\begin{array}{l}\text { 2-hydroxyethyl methacrylate } \\
\text { (HEMA),methacryloxyethyltrimellitic } \\
\text { acid anhydride (4-META) } \\
\text { di(meth)acrylates silica, } \\
\text { amorphous zirconia }\end{array}$ & $\begin{array}{l}\text { Sun } \\
\text { Medical, } \\
\text { USA }\end{array}$ & $\begin{array}{l}\text { Secure } \\
\text { primer } \\
\text { uygulama, } \\
20 \text { s sonra } \\
\text { hafif hava ile } \\
\text { kurutma. } \\
\text { Eşit } \\
\text { miktarda } \\
\text { baz ve } \\
\text { katalist } \\
\text { karıştırıarak } \\
\text { uygulama } \\
\text { ve } 40 \text { sn ışık } \\
\text { aktivasyonu. }\end{array}$ & VT3 \\
\hline
\end{tabular}

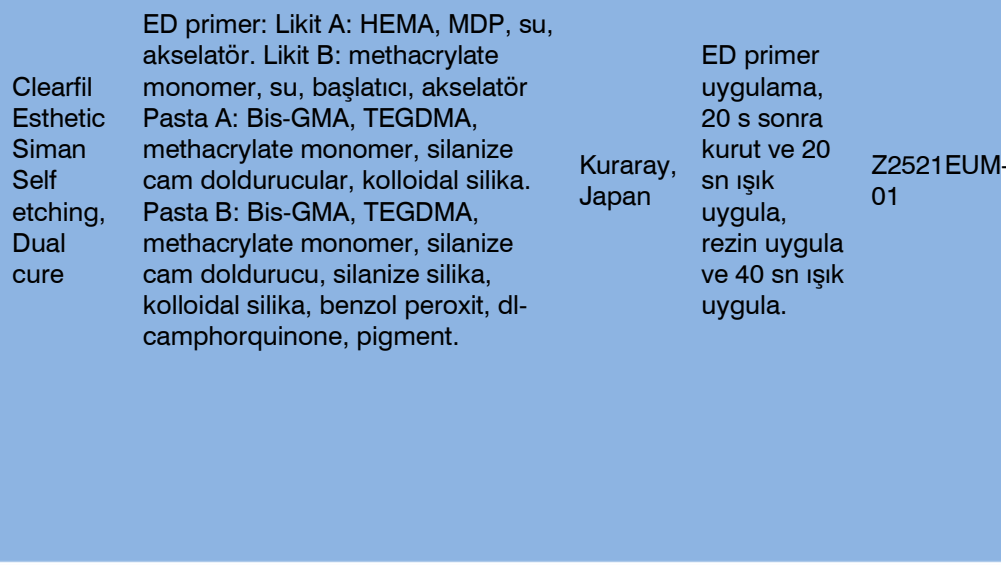


Tablo 2.

Ortalama, Standart sapma, Standart hata,
minimum and maximum değerler

\begin{tabular}{|c|c|c|c|c|}
\hline $\begin{array}{l}\text { Grup } \\
\text { Kodları }\end{array}$ & Gruplar & Ortalama & $\begin{array}{l}\text { Standart } \\
\text { sapma }\end{array}$ & Min-Max \\
\hline G1 & $\begin{array}{l}\text { Bleached dentin / } \\
\text { Secure Cement }\end{array}$ & $6,20 b^{\star}$ & 1,84 & $3,66-9,50$ \\
\hline G2 & $\begin{array}{l}\text { Bleached dentin / } \\
\text { Clearfil Esthetic } \\
\text { Cement }\end{array}$ & $6,86 a b$ & 2,6 & $3,59-11,06$ \\
\hline G3 & $\begin{array}{l}\text { Bleached dentin / } \\
\text { ozone / Secure } \\
\text { Cement }\end{array}$ & $6,65 a b$ & 1,23 & $5,00-8,96$ \\
\hline G4 & $\begin{array}{l}\text { Bleached dentin / } \\
\text { ozone / Clearfil } \\
\text { Esthetic Cement }\end{array}$ & 8,27 a & 1,9 & $5,90-11,50$ \\
\hline G5 & $\begin{array}{l}\text { Ozone / Secure } \\
\text { Cement }\end{array}$ & $4,30 \mathrm{c}$ & 1,25 & $2,64-6,59$ \\
\hline G6 & $\begin{array}{l}\text { Ozone / Clearfil } \\
\text { Esthetic Cement }\end{array}$ & $7,57 a b$ & 2,16 & $4,44-11,28$ \\
\hline $\begin{array}{l}\text { G7 } \\
\text { (kontrol) }\end{array}$ & Secure Cement & $6,25 \mathrm{~b}$ & 2,01 & $2,03-8,28$ \\
\hline $\begin{array}{l}\text { G8 } \\
\text { (kontrol) }\end{array}$ & $\begin{array}{l}\text { Clearfil Esthetic } \\
\text { Cement }\end{array}$ & $6,03 \mathrm{bc}$ & 2,24 & $2,90-8,96$ \\
\hline
\end{tabular}

*Farklı harfler istatistiksel olarak farklı grupları ifade eder $(p<0.05)$

\section{BULGULAR}

Bu çalışmada kullanılan materyaller ile igili üretici firma bilgileri Tablo 1'de verilmiştir. Deney grupları için ortalama shear bağlanma dayanımları ve standart sapmaları Tablo 2'de ve adeziv hata modlarının dağılımı Tablo 3'te verilmiştir. Tek yönlü varyans analizi ağartma işlemi veya ozon uygulamasının bağlanma dayanımını etkilediğini göstermiştir $(P<0.05)$. Ağartma tedavisi sonrası ozon uygulaması hem Secure simanda (G3) hem de Clearfil Esthetic simanda (G4) bağlanma dayanımını arttırmıştır ( $p>0.05$ ). Clearfil Esthetic siman (G4) herhangi bir işlem uygulanmadan kondanse edilen kontrol grubundan (G8) anlamlı derecede daha yüksek bağlanma dayanımı göstermiştir. Kullanılan iki faktörün birbirleriyle etkileşimi Secure siman grubunda (G3) sadece ozon uygulanan gruptan (G5) anlamlı derecede farklı sonuç göstermiştir. G5 grubu, G8 kontrol grubu dışındaki diğer tüm gruplardan anlamlı dercede daha düşük bağlanma dayanımı göstermiştir. En yüksek bağlanma dayanımı (MPa) ağartma ve ozon uygulanan Clearfil Esthetic siman grubunda gözlenmiştir (G4)

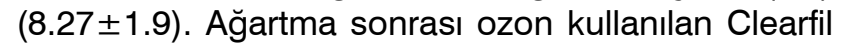
Esthetic siman grubu G6 ile benzer sonuçlar gösterirken; G4, G8'den istatistiksel olarak anlamlı derecede yüksek değerler göstermiştir. G7 ve G8 kontrol grupları G5 dışındaki diğer tüm gruplarla benzer sonuç göstermiştir.
Tablo 3.

Adeziv hata modlarının dağılımı

\begin{tabular}{|llllr|}
\hline Gruplar & $\begin{array}{l}\text { Uygulanan } \\
\text { prosedür }\end{array}$ & \multicolumn{1}{c}{$\begin{array}{l}\text { Adeziv } \\
\text { hata }\end{array}$} & \multicolumn{1}{c}{$\begin{array}{l}\text { Mix } \\
\text { hata }\end{array}$} & \multicolumn{1}{l}{$\begin{array}{l}\text { Koheziv } \\
\text { hata }\end{array}$} \\
\hline G1 & $\begin{array}{l}\text { Ağartma / Secure } \\
\text { Siman }\end{array}$ & $0 \%$ & $66.67 \%$ & $33.33 \%$ \\
\hline G2 & $\begin{array}{l}\text { Ağartma / Clearfil } \\
\text { Esthetic Siman }\end{array}$ & $0 \%$ & $25 \%$ & $75 \%$ \\
\hline G3 & $\begin{array}{l}\text { Ağartma / Ozon / } \\
\text { Secure Siman }\end{array}$ & $0 \%$ & $58.33 \%$ & $41.67 \%$ \\
\hline G4 & $\begin{array}{l}\text { Ağartma / ozon / } \\
\text { Clearfil Esthetic } \\
\text { Siman }\end{array}$ & $0 \%$ & $8.33 \%$ & $91.67 \%$ \\
\hline G5 & $\begin{array}{l}\text { Ozon / Secure } \\
\text { Siman }\end{array}$ & $0 \%$ & $41.67 \%$ & $58.33 \%$ \\
\hline G6 & $\begin{array}{l}\text { Ozon / Clearfil } \\
\text { Esthetic Siman }\end{array}$ & $0 \%$ & $16.67 \%$ & $83.33 \%$ \\
\hline $\begin{array}{l}\text { G7 } \\
\text { (kontrol) }\end{array}$ & Secure Siman & $33.33 \%$ & $50 \%$ & $16.67 \%$ \\
\hline $\begin{array}{l}\text { G8 } \\
\text { (kontrol) }\end{array}$ & $\begin{array}{l}\text { Clearfil Esthetic } \\
\text { Siman }\end{array}$ & $0 \%$ & $41.67 \%$ & $58.33 \%$ \\
\hline
\end{tabular}

*Farklı harfler istatistiksel olarak farklı grupları ifade eder $(p<0.05)$

\section{TARTIŞMA}

Endodontik tedavili renklenmiş dişlerde devital ağartma işlemi estetik restorasyonlar öncesi uygulanan konservatif tedavi yöntemidir. Bununla birlikte, ağartma sonrası dentin yüzeyinde kalan oksijen, kompozit restorasyonların bağlanma dayanımını etkilemektedir (Rueggeberg ve Margeson 1990). Dentin yüzeyindeki oksijenin yavaş uzaklaşması nedeniyle bonding işlemlerinden önce bir süre beklenmesi önerilmektedir (Howell 1981). Test materyalinin shear veya tension şeklinde uygulanması test edilen materyallerin bağlanma dayanımları hakkında bilgi vermektedir. Bununla birlikte shear bağlanma dayanımı, materyal özellikleri ve mikroyapısı üzerinde göreceli bir etki yarattığından ve uygulanan kuvvet esnasında materyalin dayanım performansına dayandığından sıklıkla kullanılmaktadır (Versluis ve ark 1997, DeHoff ve ark 1995, Della Bona ve Van Noort 1995).

$\mathrm{Bu}$ in vitro çalışmanın amacı, ağartma işlemi uygulanan veya uygulanmamış dentin yüzeyine ozon uygulamasının; iki farklı adeziv rezinin dentine shear bağlanma dayanımına etkisini incelemektir. Bu çalışmanın sonuçları kullanılan adezive veya yüzey işlemlerine bağlı olarak bağlanma dayanımları arasında farkılık olduğunu göstermiştir. Yalnızca ozon uygulanan Secure cement grubu kontrol grubuda dahil olmak üzere diğer Secure siman gruplarından daha düşük bağlanma dayanımı 
göstermiştir. Bununla birlikte ağartma sonrası ozon uygulamasının Secure siman grubunda bağlanma dayanımı açısından bir fark yaratmadığı bulunmuştur. Clearfil estetik siman uygulaması hem ağartma sonrası hem de tek başına ozon uygulaması yapılan dentin yüzeylerinde bağlanma dayanımında artış sağlamıştır. Kontrol grubuyla karşılaştııılığında bağlanma dayanımları arasında, ağartma sonrası ozon uygulanan grup dışında fark olmadığı bulunmuştur. Ağartma işlemi sırasında uygulanan hidrojen peroksitin, dentin tübüllerinde rezidüel artık oluşturduğu ve bonding ajanlarının dentin tübüllerine infiltrasyonunu azalttığı bilinmektedir (Howell 1981). Ozon uygulamasının rezidüel peroksiti uzaklaştırarak bağlanma yüzeylerini arttırdığı düşünülebilir.

Secure siman ve Clearfil estetik siman grupları arası karşılaştırmalara bakıldığında, Clearfil estetik simanın ağartma ve/veya ozon uygulanan grupların hepsinde Secure simandan daha yüksek bağlanma dayanımı gösterdiği bulunmuştur. Secure simanın tek başına uygulandığı kontrol grubu Clearfil estetik siman kontrol grubuyla benzer bağlanma dayanımı göstermiş̧tir.

Asitleme işlemindeki yetersizlikler kullanılan materyalin mekanik özelliklerini düşürebilir (Combe ve ark 1999, Abdelaziz ve Attia 2007). Ozon uygulamasının asitleme işlemi öncesi yapılmasının uygulanan adeziv sistemler arasında fark olmaksızın bağlanma dayanımında bir değişiklik oluşturmadığını rapor etmişlerdir (Abdelaziz ve Attia 2007). Diğer taraftan asitleme işlemi sonrası ozon uygulaması yüzeydeki oksijen tabakasını arttırarak uygulanan adeziv tabakasının polimerizasyonunu azaltabilir (Bayne 2002). İşlem sırasında kullanılan sakşın kollajen fibrilin su kaybetmesine neden olarak bağlanma problemleri oluşturabilir (Abdelaziz ve Attia 2007).

Adeziv hata modları incelendiğinde, adeziv hata sadece Secure siman kontrol grubunda gözlenirken, gruplar arasında en yüksek oranda hata koheziv hata olarak ağartma sonrası ozon uygulanan ve Clearfil Esthetic simanla restore edilen örneklerde gözlenmiştir. Hem Secure siman hem de Clearfil Esthetic siman self-etch dual cure rezinlerdir. Benzer içeriklere sahip olmalarına rağmen kontrol grupları arasındaki adeziv hata mod farklııklarının sebebi, materyal içeriklerinin oransal değişkenliği olabileceği gibi akışkanlık ve infiltrasyon derinlikleri arasındaki değişikliklere bağlı da olabilir. Bununla birlikte, bu çalışmada ağartma ve ozon prosedürlerinin ayrı ayrı veya birlikte uygulanması her iki simanın bağlanma dayanımları üzerinde farklı deneysel sonuçlar ortaya koymuştur. Bu çalışmanın sonuçları göstermiştir ki rezin içeriğe sahip simanlar arası üretim farkları, ağartma ve ozon uygulamaları söz konusu olduğunda bağlanma dayanımı farklııkları yaratabilir.

\section{ÖNERILLER}

Bu çalışmanın sınırları dahilinde şunlar söylenebilir:

1. Ağartma işlemini takiben ozon kullanılan veya kullanılmayan gruplar ile kontrol grubu, Secure siman ile restore edildiğinde benzer bağlanma dayanımı gösterirken, sadece ozon uygulanan grup diğer Secure siman gruplarından daha düşük bağlanma dayanımı gösterdi.

2. Clearfil Esthetic siman gruplarında; ağartma yapılan, ağartmayı takiben ozon uygulanan ve sadece ozon uygulanan gruplar benzer bağlanma dayanımı gösterirken, kontrol grubu ağartma ve ozonun kombine kullanıldığı gruptan düşük bağlanma değerleri gösterdi.

3. Ağartma sonrası ozon uygulanan Secure siman ve Clearfil Esthetic siman grupları birbirine benzer bağlanma dayanımı gösterdi ve bu değerler kontrol gruplarıyla benzer veya daha yüksekti.

4. Bu çalışmanın temellerine dayanarak, ozon uygulamasının Clearfil Esthetic simanın bağlanma dayanımını değiştirmediğini, bu nedenle bonding işlemleri öncesi ozon uygulanmasının final restorasyonun etkinliğini azaltmayacağı söylenebilir.

5. Sonuç olarak, ağartma sonrası ozon uygulaması yüzeyde kalan peroksit kalıntılarını uzaklaştırarak bonding prosedürünün etkinliğini, hem Secure siman hem de Clearfil Esthetic siman bağlantısını artırabilir. Devital ağartma yapılan dişlerde dentin yüzeyine ozon uygulaması rezin simanların bağlantısını artırabileceği söylenebilir 


\section{Ozon uygulamasının devital ağartma yapılan dentinde rezin simanın shear bağlanma dayanımına etkisi}

Amaç: Ozon uygulanan ve uygulanmayan devital ağartma yapılmış dentine iki rezin simanın bağlanma dayanımının incelenmesi

Gereç ve Yöntemler: : Seksen yeni çekilmiş sağlam insan maksiller kesici kuronları sekiz gruba ayrıldı $(n=10)$ : (G1, G2). Ağartmayı takiben ozon uygulanmayan $(10 \%$ carbamide peroxide, Opalescence Boost \%38 Hydrogen peroxide) veya uygulanan gruplar (G3, G4) $(40 \%, 50$ second, CR probe, Biozonix; High-Frequency Ozone Generator, Germany), ozonun ağartma yapılmadan uygulandığı gruplar $(G 5, G 6)$ ve herhangi bir işlem uygulanmayan kontrol grupları (G7, G8). Kuronlar akrilik rezin içine dentin yüzeyleri açıkta kalacak şekilde yerleştirildi. Örneklerde iki rezin simandan biri kullanıldı: Secure Cement (Sun Medical) (G1, G3, G5, G7); Clearfil Esthetic Cement (Kuraray) (G2, G4, G6, G8). 3 x 3 boyutunda rezin siman oluturulan gruplar setleşme süresinden (37으, $100 \%$ nemli, 24 saat) sonra shear bağlanma dayanımı ile test edildi ( $0.5 \mathrm{~mm} /$ minute). Veriler MPa olarak hesaplandı ve Kruskal-Wallis testi ile analizler yapıldı $(P<0.05)$.

Bulgular: Ağartma işleminin ozon uygulaması ile kombine kullanımı hem Secure siman (G3) hem de Clearfil Esthetic simanın (G4) bağlanma dayanımını artırdı $(p>0.05)$. Ozon uygulanan Secure siman örnekleri (G5), G1, G3, ve G7 gruplarından anlamlı derecede daha düşük bağlanma dayanımı gösterdi $(P<0.05)$. Clearfil Esthetic siman grubu (G4) kontrol grubundan (G8) anlamlı derecede daha yüksek bağlanma dayanımı gösterdi.

Sonuç: Bonding işlemleri öncesinde ozon uygulaması ağartma sonrası geride kalan peroksitin etkisini azaltabilir. Devital ağartma sonrası ozon uygulaması rezin simanın dentin yüzeyine bağlantısını artırabilir.

\section{ANAHTAR KELIMELER}

Nonvital bleached dentin, ozone, rezin siman, shear bond strength

\section{KAYNAKLAR}

Abdelaziz KM, Attia A, 2007. Bonding of contemporary adhesives to ozone-treated dentin surfaces. Rev Clin Pesq Odontol, 3(3), 165-173.

Azarpazhooh A, Limeback $\mathrm{H}, 2008$. The application of ozone in dentistry: a systematic review of literature. J Dent, 36, 104-16.

Bayne S, 2002. Bonding to dental substances. In Craig RG, Powers GM. Restorative dental materials. Mosby, St.Louis, USA, pp; 260-283.

Cavalli V, Reis AF, Giannini M, Ambrosano GM, 2001. The effect of elapsed time following bleaching on enamel bond strength of resin composite. Oper Dent, 26, 597-602.

Combe EC, Trevor Burke FJ, Douglas WH, 1999. Surfaces and interfaces, and dentin bonding systems in dental biomaterials. Kluwer Academic Publishers, Boston, USA, pp; 258-272.

Dahnhardt JE, Jaeggi T, Lussi A, 2006. Treating open carious lesions in anxious children with ozone. A prospective controlled clinical study. Am J Dent, 19, 267-70.

DeHoff PH, Anusavice KJ, Wang Z, 1995. Three dimensional finite element analysis of the bond strength of the shear bond test. Dent Mater, 11(2), 126-131.

Della Bona A, Van Noort R, 1995. Shear vs tensile bond strength of resin composite bonded to ceramic. J Dent Res, 74(9), 1591-1596.

Freire A, Souza EM, de Menezes Caldas DB, Rosa EA, Bordin CF, de Carvalho RM, Vieira S 2009. Reaction kinetics of sodium ascorbate and dental bleaching gel. J Dent, 37, 932-936.

Howell RA, 1981. The prognosis of bleached rootfilled teeth. Int Endod J, 14, 22-26.

Huth KC, Paschos E, Brand K, Hickel R, 2005. Effect of ozone on non-cavitated fissure carious lesions in permanent molars. A controlled prospective clinical study. Am J Dent, 18, 223-8.

Khoroushi M, Feiz A, Ebadi M, 2009. Influence of intermediary filling material on microleakage of intracoronally bleached and restored teeth. Dent Res J (Isfahan), 6, 17-22.

Knezevi'c A, Tarle Z, Negoveti'c Mandi'c V, Prskalo K, Panduri'c V, Jankovi'c B, 2007. Primary fissure carious lesion reversal using ozone. Acta Stomatol Croat, 41, 31-8. 
Kwon TY, Kim YK, 2013. Effective application duration of sodium ascorbate antioxidant in reducing microleakage of bonded composite restoration in intracoronally-bleached teeth. Restor Dent Endod, 38(1), 43-47.

Moosavi H, Moghaddas MJ, Ghoddusi J, Rajabi O, 2010. Effects of two antioxidants on the microleakage of resin-based composite restorations after nonvital bleaching. J Contemp Dent Pract, 11, E033-E040.

Nagayoshi M, Kitamura C, Fukuizumi T, Nishihara T, Terashita M, 2004. Antimicrobial effect of ozonated water on bacteria invading dentinal tubules. J Endod, 30(11), 778-781.

Rueggeberg FA, Margeson DH, 1990. The effect of oxygen inhibition on an unfilled/filled composite system. J Dent Res, 69, 1652-1658.

Schmidlin PR, Zimmermann J, Bindl A, 2005. Effect of ozone on enamel and dentin bond strength. J Adhes Dent, 7, 29-32.

Shinohara MS, Peris AR, Rodrigues JA, Pimenta LA, Ambrosano GM, 2004. The effect of nonvital bleaching on the shear bond strength of composite resin using three adhesive systems. J Adhes Dent, 6, 205-9.

Shinohara MS, Peris AR, Pimenta LA, Ambrosano GM, 2005. Shear bond strength evaluation of composite resin on enamel and dentin after nonvital bleaching. J Esthet Restor Dent, 17, 22-9.

Spyrides GM, Perdigao J, Pagani C, Araujo MA, Spyrides SM, 2000. Effect of whitening agents on dentin bonding. J Esthet Dent, 12, 264-70.

Türkün M, Türkün LS, 2004. Effect of nonvital bleaching with $10 \%$ carbamide peroxide on sealing ability of resin composite restorations. Int Endod J, $37,52-60$.

Versluis A, Tantbirojn D, Douglas WH, 1997. Why do shear bond tests pull out dentin? J Dent Rest, 76(6), 1298-1307.

Yazışma Adresi:

Doç.Dr. Betül ÖZÇOPUR

Yüzüncü Yıl Üniversitesi Diş Hekimliği Fakültesi

Endodonti AD 65080 Kampüs / Van

Tel: +90 (432) 2251744

Faks: +90 (432) 2251744

E-mail: betulozcopur@hotmail.com 